$+x$

\title{
A EMANCIPAÇÃO DO EXECUTIVO DE MARKETING
}

\section{- Raimar Richers}

Professor Fundador do Departamento de Mercadologia da EAESP/FGV.

* RESUMO: Durante séculos, o comerciante foi visto como uma espécie de pária pela sociedade. Aos poucos, no entanto, ele se tornou mais aceito e respeitado, até emergir - mas isto só no século $X X$ - no topo da empresa como executivo de marketing, com autonomia e poderes. $O$ artigo descreve a lenta metamorfose desse processo e as mudanças pelas quais a sociedade tinha que passar, para torná-lo possível.

* PALAVRAS-CHAVE: Conceito de marketing, Revolução Industrial, capitalismo, propósito de lucro, produção em massa, diferenciação, segmentação, importância da informática.

* ABSTRACT: For centuries the trader was looked upon as a pariah of society. Slowly however he became more accepted and respected, until emerging - though only in the 20th century - at the top of the enterprise as a full-fledged marketing executive. The article describes how this metamorphosis came about and in what respects society had to change for this to become possible.

* KEY WORDS: Marketing concept, Industrial Revolution, capitalism, profit motive, mass production, differentiation, segmentation, importance of information.

São Paulo, 33(1):52-65 


\section{INTRODUÇÃO}

Estamos vivendo uma fase de evolução econômica, em que a sobrevivência da empresa depende, em grau crescente, da sua capacidade de adaptação aos mercados consumidores. Nos países altamente industrializados do mundo, essa transição da economia da produção para a economia do consumo é um fato inconteste, mas ela também ocorre em países em desenvolvimento.

O Brasil é um exemplo disso. Entre nós, muitas empresas que ainda há poucos decênios atrás vendiam sem grande esforço o que conseguiam produzir, oferecendo sempre o que queriam vender, são hoje obrigadas a se dedicarem intensamente a melhor compreender o que a clientela deseja e a se adaptar a essas predileções. Independentemente da conjuntura e da crise, nota-se isto sobretudo nos setores altamente competitivos, como o do vestuário e o do comércio varejista.

É natural que uma transição desta natureza e intensidade seja acompanhada por repercussões internas na empresa, que forçam o administrador a alterar as suas ações e atitudes. Também isto se verifica no Brasil de hoje: gradativamente, 0 nosso administrador está abandonando a improvisação a favor do planejamento e da ação estratégica. Ao mesmo tempo, os pesos relativos das posições-chave estão sendo reavaliados nas empresas, freqüentemente a favor-do executivo de marketing, diretor comercial, gerente de vendas ou qualquer que seja o título oficial dos que respondem pela área de vendas nas empresas.

Ao que parece, esse processo de transição provém de longa data, mas somente há poucos decênios está se fazendo sentir com todo o seu poder, acumulado durante séculos. Com o intuito de caracterizar esse processo e para podermos melhor entender as razões do destaque com que o executivo de marketing atua na empresa moderna, analisaremos, neste artigo, a história econômica sob o enfoque específico desta transição.

Comecemos pelo fim: o conceito de marketing como ele é entendido hoje e as múltiplas transformações que ele já sofreu desde que foi criado mais ou menos em redor do início do nosso século.

\section{Definimos então}

\section{marketing como as}

\section{atividades}

\section{sistematicamente}

voltadas à busca e à

realização de trocas

com o meio ambiente.

\section{UM CONCEITO REVOLUCIONÁRIO}

Ao traduzir o conceito norte-americano marketing, em meados de 1954, a Escola de Administração de Empresas de São Paulo optou por úm desdobramento da expressão em "Mercadologia" e "mercadização". Por Mercadologia entendemos o estudo sistemático da mercadização. ${ }^{1}$

Apesar de sua juventude, o marketing já passou por uma série de fases conotativas bem distintas e em parte até divergentes. Houve épocas em que as definiçōes se concentravam nos aspectos primordialmente legais, relacionados à transferência de posse quando da compra e venda de bens. Em outras ocasiões, a ênfase fôra dada a aspectos relacionados à distribuição, sobretudo quando nos EUA surgiram conflitos entre os interesses de poderosos grupos de produtores e distribuidores de bens.

Durante muito tempo prevaleceu como definição mais divulgada a da Associação Americana de Marketing (AMA), que caracterizava essa área como abrangendo todas as atividades que envolvem o fluxo de bens e serviços entre o produtor e o consumidor. Mas, essa definição não resistiu às críticas de inúmeros representantes, não só no meio acadêmico, como também dos praticantes de marketing. Ela deu lugar a uma interpretação mais ampla e mais voltacta a dois aspectos primordiais: a responsabilidade das funçōes administrativas dentro do processo de marketing na empresa (o chamado managerial marketing) e a abordagem sistêmica que se preocupa com a integração orde-
1. Mantive esta frase da ediçāo original deste artigo (publicado no número 1 da RAE de maio/agosto 1961), porque ela demonstra como é fácil cair em equívocos. Na época, ninguém de nós duvidava que 0 anglicismo americano marketing teria que ser traduzido e aportuguesado para poder ser aceito no Brasil... 


\section{"No fundo do seu}

coração, nada é mais

estranho ao comerciante

do que o desejo

do lucro..."

nada entre os diversos instrumentos que participam de um processo mercadológico qualquer. Uma nova modificação conceitual do marketing surgiu em conseqüência das repercussões dos movimentos consumistas mundiais, de um lado, e, do outro, do reconhecimento de que o conceito de marketing poderia ter aplicação e utilidade em áreas não necessariamente restritas à atuação das empresas privadas.

Hoje, aplica-se também às funções do Estado ou de uma comunidade social, bem como às atividades de organizações que não necessariamente visam lucros, tais como igrejas, hospitais ou partidos políticos. Do outro lado, voltou-se também para dentro das organizações, através do endomarketing, que trata de "vender" $^{\prime \prime}$ a idéia do marketing para os funcionários das empresas. Ao mesmo tempo se expandiu para além das fronteiras para ajudar as empresas nos seus esforços de globalização. Com isto, o marketing começou a agir em várias áreas e direções, ao ponto de confundir muita gente quanto ao seu conceito e até seus objetivos primordiais.

Em função destas mudanças freqüentes de direcionamento e amplitude, torna-se difícil definir o conceito de marketing. Mas, há um exemplo consenso entre teóricos e praticantes que a disciplina tem muito a ver com trocas, que essas trocas precisam ser intencionais e sistemáticas, além de voltadas ao mundo externo à empresa. Definimos então marketing como as atividades sistematicamente voltadas à busca e à realização de trocas com o meio ambiente. Essas trocas podem envolver quaisquer tipos de valores, tanto objetivos tangíveis (tais como bens de consumo e dinheiro) quanto intangíveis (como serviços ou mesmo idéias).

Mas, por mais ampla que possa ser a gama dos objetos transacionados, não é qualquer tipo de troca que merece ser caracterizado como mercadológico. Por exemplo, a troca de informações não planejada entre duas agências noticiosas não tem conotação mercadológica. Para que isto ocorra, deve haver o intuito da continuidade no processo de troca entre os partidos, ou seja, ela deve ser ao mesmo tempo intencional, sistemática e voltada a uma expectativa de resultados previsíveis, sejam eles quantificáveis ou não.

Desta maneira, uma empresa que se dedica regularmente à oferta e à transação de produtos, ou serviços, exerce uma função mercadológica tão indiscutível quanto, digamos, uma instituição beneficente voltada à busca ordenada de fontes para doaçōes que ela encaminha a públicos-alvo predefinidos. Mas, a "troca" de presentes de Natal entre os membros de uma família não é uma ação mercadológica.

Tudo indica então que, ao longo deste século XX, o conceito de marketing sofreu múltiplas variações. Pode-se até afirmar que ele foi usado como se fosse uma bola de futebol, ferrenhamente disputada por equipes com posições adversas. Mesmo assim, manteve-se dentro de um campo claramente delimitado por um princípio inabalável: a exigência da empresa de se adaptar aos desejos do consumidor. Para muitas empresas esta é uma exigência bastante desagradável porque implica mudanças culturais e estruturais que, por vezes, lhe são totalmente adversas, como por exemplo, pagar comissões elevadas a vendedores e intermediários, ter que pesquisar quais são efetivamente os desejos da sua clientela, interferir na apresentação e na qualidade dos seus produtos ou redefinir a paralelograma das forças políticas da organização. Tudo isto não só requer mudanças comportamentais, como também investimentos elevados, muito pouco "produtivos" na opinião de muitos administradores, mas indispensáveis para quem quer se tornar uma empresa efetivamente marketingminded.

Foi inevitável também que, com a adaptação da empresa à demanda, houvesse uma mudança significativa nas responsabilidades internas da empresa. 
Quem perdeu uma boa parte da autonomia de decisão foram os executivos de produção, mas também os financeiros e por vezes até a própria presidência em função das responsabilidades crescentes dos homens que são responsáveis pelas vendas. $E$ com isto mudaram-se também as funções do executivo de marketing que deixou de ser mero gerente de vendas para agora assumir a responsabilidade de investigar as forças e tendências do mercado, provocar a adaptação das linhas de produtos a essas forças, fazer com que os produtos atingissem os mercados certos, no momento certo, em quantidades certas e através de sistemas de distribuição certos, e, finalmente, comprometer-se a realizar tudo isto dentro de um orçamento que assegurasse um retorno positivo para a empresa. ${ }^{2}$

Hoje, esta visão de marketing, com toda a sua complexidade de funções, é um fenômeno que aceitamos normalmente nas empresas, porque passou a fazer parte da nossa realidade. Mas, não era sempre assim. Por que não? O que mudou na sociedade e nas empresas que justificasse a emancipação do executivo de marketing, atribuindo-lhe a responsabilidade e o poder de que dispõe atualmente?

\section{AS ORIGENS DO DESPREZO PELO COMÉRCIO}

Houve épocas, na primitiva história do Ocidente, em que o comércio foi a coluna vertebral para a economia de muitas comunidades. Contudo, no século VIII, as atividades comerciais sofreram um golpe mortal com a invasão dos islamitas na Europa e decadência da navegação marítima. O europeu viu-se obrigado a procurar novos meios de vida; encontrou-os na agricultura. A terra passou a ser "a única fonte de riqueza. Todas as classes da populaçāo, desde o imperador, até o mais humilde de seus servidores, viviam, direta ou indiretamente, dos produtos do solo". ${ }^{3}$ Criaram-se os latifúndios, mas perderam-se os mercados externos. Os poucos comerciantes eram os judeus, que se dirigiam a uma clientela restrita, composta, sobretudo, da aristocracia.

Somente "no decurso do século $X$ reapareceu, na Europa continental, uma classe de comerciantes profissionais, cujo progresso,
Já no início do

capitalismo, o produtor

perde o contato direto

com o consumidor é

obrigado a procurar

intermediários

varejistas e atacadistas.

bem lento de inicio, tomou velocidade no avanço do próximo século." 4 Apesar de os pioneiros desse movimento terem sido, na sua maioria, vagabundos e cavalheiros ladrões (os temidos Raubritter), foram eles os porta-bandeiras do renascimento econômico da Idade Média.

Socialmente, porém, os mercadores eram párias, invejados talvez, mas desrespeitados, tanto pelos nobres, quanto pela Igreja. "A nobreza nunca teve senão desprezo por esses novos ricos, surgidos do desconhecido, cujas insolentes boas fortunas não podia suportar .... Quanto ao clero, a atitude em relação aos comerciantes era ainda mais desfavorável. Aos olhos da Igreja, a vida comercial era perigosa à segurança da alma... Aos canonistas o comércio parecia ser uma forma de usura. Condenavam eles a procura do lucro, confundindo-a com a avareza." 5

Tivemos, então, uma situação de conflito nesta época de recuperação econômica da Idade Média. De um lado, o comércio constituiu o elixir revitalizador do processo; do outro, o comerciante foi marcado pelo desdém da elite que determinava os valores da época - o clero e a nobreza. É neste conflito que podemos encontrar as raízes do preconceito que obstruiu o franco desenvolvimento mercantil no passado e ainda hoje afeta a posição social do comerciante.

\section{AS ECONOMIAS FECHADAS DA IDADE MÉDIA}

Do século XII em diante, uma nova camada social se estabelece: a classe média. O seu campo de ação é, por excelência, o burgo; a sua ocupação predileta a manufatura.

Quatro são os fatores que determinam
2. 0 autor desenvolveu um sistema de marketing denominado os 4 As, que descreve a interdependênçia das funçōes de marketing a partir dos conceitos de Análise, Adaptaçāo, Ativaçāo e Avaliaçāo (RICHERS, Raimar. O que é Marketing. Sāo Paulo, Editora Brasiliense, $12^{a}$ ediçăo, 1991).

3. PIRENNE, Henri. História Económica Y Social de La Edad Média. México/Buenos Aires, Fondo de Cultura Econômica, $6^{\mathrm{a}}$ edição, 1955, p. 12.

4. PIRENNE, Henri. Medieval $\mathrm{Ci}_{-}$ ties, their Origins and the Revival of Trade. Garden City, N.Y, Doubleday \& Company, Inc., 1956, p. 80.

5. PIRENNE, Henri. Idem, ibidem, p. 87. 
6. WEBER, Max. História Económica General. México, Buenos Aires, Fonde de Cultura Económica, $2^{\mathrm{a}}$ edição, 1956, p 205.

7. SOMBART, Werner. Der Moderne Kapitalismus München und Leipzig, Verlag von Duncker \& Humblot, vol. $\mid / 1,1928, p$. 190.

8. SOMBART, Werner. Idem, ibidem. p. 291. a relação produção-comércio na Idade Média:

1. O elevado grau de auto-suficiência das cidades;

2. a produção sob encomenda;

3. a identidade produtor-comerciante;

4. a ausência do propósito de lucro.

Expliquemos brevemente o que devemos entender por esses fatores:

1. Com exceção da Hansa alemã, "não se pode falar na Idade Média de uma política mercantil das cidades". "O crescente progresso do artesanato torna o intercâmbio entre centros do consumo antieconômico e até supérfluo. As trocas mercantis restringem-se quase que somente às feiras, nas quais artesãos e camponeses (que trabalham os campos em volta às cidades) oferecem uma parcela da sua produção.

2. A maioria dos bens, porém, é produzida sob encomenda. Quem necessita de um par de sapatos (ou qualquer outro produto manufaturado) procura a sua "oficina" predileta e manda fazê-lo sob medida. $\mathrm{O}$ contato direto entre produtor e consumidor torna a organização empresarial simples e eficiente. Os intermediários são desnecessários e a demanda é, em regra, assegurada sempre que persiste a boa qualidade.

No auge do capitalismo, a produção por encomenda é progressivamente substituída pela produção especulativa, em que o fabricante produz sem ter a certeza se o consumidor deseja ou não os seus produtos e em que quantidades.
3. Enquanto prospera esse sistema, o artesão, como membro da guilda, é o dono absoluto de produção e comércio. Nele se concentram todas as qualidades indispensáveis ao empresário da época: a capacidade técnica, a visão artística e a habilidade do ensino. Além do mais, o artesão "funciona como organizador e diretor da produção ... mas é também o comerciante. Todas as atividades de compra e venda, toda a organização da distribuição, em resumo, tudo aquilo que mais tarde é realizado com diligência especulativa por algumas personalidades, excepcionais, constitui o seu capital pessoal". ${ }^{7}$

4. Mas o que mais distingue o artesão da Idade Média do seu sucessor - o empresário capitalista - é a motivação que o faz agir. $\mathrm{Na}$ opinião de Sombart, o elemento propulsor das atividades produtivas da Idade Média é o que ele chama de "idéia de alimentação". Diz ele: "No fundo do seu coração, nada é mais estranho ao comerciante do que o desejo do Iucro no sentido do empresariado moderno; assim, ele näo pretende, nada mais e nada menos, do que ganhar, bem ou mal, a sua subsistência". 8

Podemos disso concluir que, na Idade Média, o comércio exerce uma função meramente complementar à produção, pois o artesanato pouco se preocupa em granjear mercados localizados além do seu alcance imediato, seja porque o espírito conquistador do capitalista lhe é desconhecido, seja porque a atividade mercantil continua a ser mal vista pelo clero e pela nobreza.

\section{O NASCIMENTO DO CAPITALISMO E A EXPANSÃO DOS MERCADOS}

A época que abrange a passagem do século XV ao século XVI traz consigo uma profunda alteração na vida social da Europa. No setor político formam-se os estados modernos, no setor econômico surge a empresa capitalista. A criação desta é favorecida pela descoberta de novos mercados (Oriente e Américas), pelo vasto abastecimento de matérias-primas e metais preciosos, pela invenção de processos de produção (alto-forno), pelo desenvolvimento da contabilidade em dupla partida, pela formação de mercados 
organizados (A Bolsa de Antuérpia) e pela expansão dos serviços postais em âmbito internacional.

Por sua vez, o século XVII contribui decisivamente ao fortalecimento do Capitalismo. Os seus traços principais são o aparecimento de um espírito empreendedor (fomentado pelas perseguições religiosas e pela filosofia comercial dos puritanos), a expansão do mercantilismo, as inovações técnicas (sobretudo na indústria têxtil), o aumento das fortunas burguesas, a criação de sociedades por cotas, de bancos comerciais e da imprensa, como meios de concentração e divulgação de riqueza. ${ }^{9}$

Entre as muitas transformações radicais que o capitalismo introduz no sistema econômico das nações, figura a dissolução das quatro características citadas que determinam a relação entre produção e comércio na Idade Média. Os mercados se expandem, inicialmente além das áreas urbanas, posteriormente além das fronteiras nacionais. O produtor perde o contato direto com o consumidor e é obrigado a procurar intermediários varejistas e atacadistas. Quantidades crescentes de bens são vendidas em feiras, estabelecimentos lojistas, mercados bolsistas e pelo correio. A expansão das empresas e o aumento das funções administrativas obrigam a uma separação entre as responsabilidades de produção e de vendas dentro das próprias organizações.

Finalmente e acima de tudo, um novo espírito começa a dominar o empresário: o desejo de auferir e aumentar o lucro, de expandir as suas atividades empresariais e entrar em franca competição com os seus concorrentes. Em conseqüência, a relação entre quantidades oferecidas e procuradas se altera nitidamente. $\mathrm{O}$ consumidor começa a ter alguma liberdade de escolha entre maior variedade de bens e torna-se ciente desse privilégio. Por enquanto, contudo, essa liberdade se restringe a um grupo limitado de bens, sobretudo aos bens de luxo (obras de arte, vestimentas caras, residências feudais etc.) que, de um lado, permitem uma individualização e, de outro, são acessiveis a uma restrita camada social (sobretudo à nobreza) que dispõe de uma renda elevada.

Para que o mercado moderno possa constituir-se, duas condições ainda terão que ser estabelecidas: a criação e a aplicação de processos tecnológicos capazes de permitir a produção em larga escala e uma distribuição da renda nacional de dar vazão aos bens produzidos em massa.

\section{A REVOLUÇÃO INDUSTRIAL E O MERCADO VENDEDOR}

A primeira destas duas condições é cumprida inesperada e radicalmente durante a segunda parte do século XVIII, quando uma série de invenções técnicas abre caminho à industrialização e ao transporte coletivo. As conseqüências desta "maior das modificações na história humana", na opinião de Taussig, foram, mais tarde, rotuladas de "Revolução Industrial". "A característica fundamental (da revolução industrial) reside na realização da divisão do trabalho por meio da dissecação dos estágios da produção em operaçōes separadas, cada uma das quais é repetida. continuamente, tornando possivel a sua execução por máquinas. "10 As vantagens econômicas da divisão do trabalho decorrem, em essência, de duas fontes: do melhor aproveitamento das forças naturais (sobretudo da água, do vapor e do carvão) e da combinação racional dos fatores de produção. Em conseqüência, quantidades crescentes de bens podem ser produzidas (e transportadas) a custos unitários decrescentes.

Uma vez que este processo se reproduz e acumula quase que automaticamente, também o mercado se transforma. Acima de tudo, a separação entre produtor e consumidor torna-se definitiva. Em outras palavras, a produção por encomenda é progressivamente substituída pela produção especulativa, em que o fabricante produz sem ter a certeza se o consumidor deseja ou não os seus produtos e em que quantidades. Nos séculos XVIII e XIX essa tendência é francamente acelerada por dois fatores: a aceitação do
9. Para uma análise minuciosa dos primeiros dois séculos do capitalismo, ver SOMBART, Werner. Op. cit., val, II/1.

10. TAUSSIG, F.W. Principles of Economics. New York, The Macmillan Company, $3^{z}$ ediç̧āo, vol. 1, 1923, p. 35. 
No século XIX, surge

uma ameaça séria ao

sistema capitalista:

- despertar da consciência

social dos assalariados. papel-moeda como unidade corrente de troca e a expansão do sistema de créditos bancários.

Entre os múltiplos problemas que o administrador capitalista enfrenta durante esta fase de transição, surge a necessidade de reduzir o seu risco de não-venda face à falta de contato direto com o mercado consumidor. A maneira pela qual ele procura resolver este problema consiste, inicialmente, no fortalecimento das vias de distribuição. Por conseguinte, "no decorrer do século XVIII, o comerciante por atacado se separa definitivamente dos varejistas $e$ forma uma camada específica da organização mercantil". ${ }^{11}$ As técnicas prediletas do atacadista são: o leilão de mercadorias em bolsas organizadas, o comércio à base de amostras, a consignação de mercadorias a terceiros (sobretudo no comércio exterior) e a utilização comercial do correio postal.

Excetuando-se as crises de adaptação (desempregos em massa, sobretudo na Inglaterra), a revolução industrial e o liberalismo econômico que a acompanham trouxeram vários decênios de prosperidade. Nunca antes e nunca depois o capitalismo floresceu tanto e tão rapidamente.

Para o nosso tema da transição, o que 11. WEBER, Max. Op. cit. p 249.

12. SOMBART, Werner. Op. cit vol III/, p. $190+$

13. Este fato levou Th. R. Malthus a escrever a sua famosa obra clássica Essay on the Principles of Population (1978) que, durante vários decênios, causou agitaçã̃o devido aos seus traços "pessimistas" sobre os efeitos da superpopulaçāo.

14. EHRENBURG, Richard. Em seu artigo intitulado "Handel" no Handwörterbuch der Staatswissenschaften. Jena, Verlag von Gustav Fischer, volume 5 , $4^{\text {a }}$ ediçāo, 1923, p. $23+$, demonstrou que esse preconceito contra o comércio sobreviveu até o nosso século. se média que está ligada ao financiamento e à distribuição dos produtos manufaturados em série. Por conseguinte, na média dos anos, a procura pelos bens $e$ serviços tende a se expandir mais rapidamente do que a capacidade produtiva das fábricas, colocando o produtor numa situação privilegiada frente ao consumidor.

Compreende-se pois, que, numa situação tão francamente favorável ao produtor, as funções da distribuição sejam relegadas a um segundo plano dentro da organização empresarial. É o que se verifica ainda no século XIX: de todos os administradores de cúpula, o executivo responsável pelas vendas é quem menos influência exerce na empresa e menos voz tem nas decisões administrativas. Além do mais, o homem ligado ao comércio continua a ser visto com maus olhos, carm regando sobre si o peso de um preconceito social. ${ }^{14}$

\section{CRISES DE ADAPTAÇÃO E REIVINDICAÇÕES SOCIAIS}

Até aproximadamente os fins da primeira metade do século XIX, a defasagem entre quantidades procuradas e oferecidas nos mercados conduz a uma confiança inabalável no sistema capitalista e estimula o processo especulativo da produção. O emprego de capitais alheios para financiar programas de expansão torna-se comum e aumenta os riscos da empresa. Ao mesmo tempo, cresce a separação entre o produtor e o consumidor, acelerada pela reação conjunta da concentração de grupos empresariais e da ampliação geográfica dos mercados. Por conseguinte, o capitalismo vê-se ameaçado por dois males por ele mesmo gerados: o superinvestimento e a perda de controle do mercado. Todavia, uma seqüência de crises econômicas consegue salvar o sistema do colapso, porque elimina a empresa marginal do processo de produção.

Ao mesmo tempo, porém, surge uma nova força que ameaça a estrutura capitalista: o despertar da consciência social dos assalariados, que demandam uma participação nos benefícios que o sistema concentrou na mão de uma minoria. Ansioso por conservar o status quo e como medida de autodefesa na luta entre con- 
correntes, o empresário resiste tenazmente a essas reivindicações, prejudicando a sua própria classe, que poderia ter-se beneficiado de uma redistribuição da renda nacional e da ampliação dos mercados de consumo.

Nesta situação, o intervencionismo estatal se revela como "anjo-da-guarda" do sistema de livre iniciativa, ainda que isto possa parecer absurdo à primeira vista. No entanto, não foram os movimentos trabalhistas que provocaram uma repartição mais equiitativa da renda, mas antes a legislação social imposta às empresas pelo estado democrático moderno, muitas vezes com fito exclusivamente fiscal. Porém, a intenção aqui pouco importa; o que vale é o resultado e este favoreceu a empresa, sempre que esta se viu ameaçada pelas consequiências do baixo poder aquisitivo das massas populares.

\section{A ALVORADA DA FILOSOFIA DE MABKETING}

É neste ambiente de fomentação e resistência social que surge o novo conceito de vendas que, mais tarde, toma o nome de marketing. Ao descobrir que uma acentuada consciência social se desenvolve na classe média e no proletariado, alguns pioneiros procuram encontrar meios mais eficazes de conquistar a simpatia da grande massa de consumidores em potencial. Os vendedores recebem instruções mais precisas, para evitar que se tornem meros tomadores de pedidos. $\mathrm{E}$, para destacar as qualidades dos seus produtos, alguns empresários começam a utilizar a propaganda, a embalagem, a rotulagem e a marca, como instrumentos promocionais.

Assim, transforma-se a atitude do empresário frente ao mercado, até o ponto de se considerar o consumidor um "rei", cujos desejos e preferências devem ser satisfeitos, inclusive à custa de sacrifícios temporários. A importância de uma renda nacional amplamente distribuída, tanto no sentido pessoal quanto no geográfico, é gradualmente reconhecida. A oposição contra a legislação social se transforma numa atitude de expectativa e, às vezes, até de apoio ponderado. Mas estas batalhas não são vencidas sem intensos conflitos entre as classes sociais e sobretudo entre os empresários e seus empre- gados, os proletários na expressão sarcástica de Marx.

Os empresários mais perspicazes introduzem programas ambiciosos e dispendiosos de assistência social, firmados na noção de que um trabalhador sadio, satisfeito e bem preparado produz mais a menores custos e de que uma comunidade próspera e bem acomodada constitui um bom mercado, tanto trabalhista quanto consumidor. Com este critério de autodefesa e a indulgência social do "viver e deixar viver" em mente, o administrador moderno forja novas armas de penetração psicológica no campo das relações humanas, relações públicas e relações industriais.

No século XX,

o comerciante se libera

do estigma da

improdutividade e se

transforma num

executivo com poderes

de decisão.

Paralelo a este processo de transformação de atitudes, corre um movimento interno nas empresas que visa a adaptação estrutural da organização às novas tendências. O principal beneficiado deste movimento é o administrador de vendas, que assume uma posição de reconhecida responsabilidade e autoridade. A função distribuidora de bens e serviços é aceita como parte integrante do processo econômico total, em que a produção cria a utilidade de forma, e a distribuição, as utilidades de tempo, local e propriedade. Socialmente, o comerciante se libera do estigma da improdutividade e se transforma num executivo com poderes de decisão.

\section{MARKETING: UMA "INVENÇ̃̃O" AMERICANA}

O fato do conceito de marketing surgir nos Estados Unidos da América é sintomático da liderança econômica e política 
A produção e distribuição em massa tornam os EUA os legítimos herdeiros da Revolução Industrial, ao colocarem as grandes inovações do século XIX a serviço de sua economia. que esse país assume, sobretudo após a segunda Guerra Mundial. Enquanto as grandes empresas européias procuram conservar as suas posiçōes no mercado por meio da formação de cartéis, o administrador amexicano adota uma diretriz bem mais sadia e duradoura de autodefesa: a de criar mercados novos. Evidentemente, o clima lhe é bastante favorável, dado o vasto potencial geográfico e humano à sua disposição.

Assim, os Estados Unidos se tornaram os legítimos herdeiros da Revolução Industrial, ao colocarem as grandes invenções do século XIX a serviço de sua economia, por meio de um engenhoso sistema de integração entre produção e distribuição em massa. ${ }^{15}$

De vital importância para o funcionamento separado, mas, ao mesmo tempo, integrado das funções de produção e de distribuição era, nos EUA, a ferrovia. Foi ela que abriu as frentes para os mercados distantes do leste americano e também de seu vasto interior. Tedlow descreve isto com muita propriedade ao analisar o caminho agitado de organizações que souberam se aproveitar desta oportunidade única - como a Coca-Cola, a Ford e a Sears. ${ }^{16}$

Desse sistema resultou um novo tipo de produto que hoje domina os mercados de consumo da maior parte do mundo: o artigo altamente padronizado, de preço baixo e resistência limitada, acessível a um grande número de compradores - o produto massificado.

Porém, não é da noite para o dia que o novo tipo de produto consegue firmar a sua posição no mercado. Antes, várias barreiras tinham que ser sobrepujadas, a principal sendo a resistência do atacadista que, nas primeiras décadas do nosso século, praticamente controlava a distribuição de bens e se opunha à introdução de novas técnicas de venda.

Após a Primeira Guerra Mundial, muitos empresários norte-americanos perce- bem a sua posição precária diante do desequilibrio entre a alta capacidade instalada das fábricas e o limitado poder aquisitivo da população. Ao mesmo tempo, verificam que o sistema de distribuição em vigor se tornou bastante inadequado para fazer face às novas responsabilidades de promoção e criação de mercados em massa. A essa altura, os fabricantes procuram intercalar-se na esfera do intermediário, com o intuito de reconquistar o contato com o consumidor e de exercer um controle direto sobre as vendas.

Trava-se uma luta aberta entre fabricantes e atacadistas, que até hoje continua acesa. Nessa luta, a mercadologia firma a sua posição no campo da atividade administrativa, Phelps expressa isso quando afirma que "de todas as tendências históricas no campo do marketing, nenhuma outra é täo distintamente nítida quanto a tendência do fabricante de assumir maior controle sobre a distribuição de seu produto" 17

E com o tempo o seu esforço é compensado: os seus elos de ligação com o varejo aumentam, e a sua dependência do atacado diminui. Na época, R. S. Alexander, estimou que da totalidade dos bens vendidos por varejistas americanos em 1929, 53,4\% tinham sido supridos por atacadistas; desde então essa percentagem caiu até atingir $38,4 \%$ em 1954 . Nos mesmos anos, a cada varejista correspondiam, respectivamente, 83,2 e 94,1 habitantes, o que indica o crescimento das lojas, cujas vendas médias anuais (já deflacionadas) aumentaram de $\$ 45.000$ por estabelecimento em 1929 para $\$ 85.000$ em 1954. ${ }^{18}$

É interessante observar que uma tendência bem semelhante pode ser constatada no Brasil dos anos 60. Na época (como hoje, 1992, outra vez) os nossos industriais procuravam anular o atacadista do processo de distribuição, dirigindo-se diretamente ao varejista ou organizando as suas próprias cadeias de lojas diretamente supridas pelas fábricas. No Brasil, um dos fatores que mais acelera esse processso foi a reincidência do IVC (Imposto de Vendas e Consignações), além do desejo de um controle mais direto sobre as vias de distribuição, a insatisfação com o atacadista, mas sobretudo o rápido avanço industrial da nação, provocado pela política de substituição das importações. 


\section{O ESFORÇO DE ADAPTAÇÃO AOS MERCADOS}

Nos EUA, não houve muito tempo para festejar a vitória sobre os atacadistas. Logo mais, surgiu um outro problema decorrente da massificação dos produtos: ele foi desde a provocar uma tal padronização que os consumidores não conseguiam mais distinguir entre as marcas dos concorrentes. Era, portanto, preciso diferenciar a oferta.

Inicialmente, a maioria dos produtos procura resolver esse problema por meio da intensificação da propaganda, freqüentemente para descobrir que esta só produz vendas se o produto for do agrado do consumidor. Isto a leva ao estudo econômico e, posteriormente, psicológico do consumo, e à adaptação dos meios publicitários à procura. Desta forma, a propaganda deixa de ser um mero instrumento auxiliar de vendas, para ocupar a dinâmica posição de criadora de mercados, abrindo o caminho ao publicitário como "sócio" mais influente do executivo de marketing nas empresas.

Simultaneamente, o próprio produto sofre uma modificação, ditada menos pelos avanços tecnológicos do que pelas condições do mercado. Maior atenção é dedicada à marca, com a sua dupla função de protetora legal e de símbolo de distinção e de qualidade. Desenvolvemse as artes da embalagem e da rotulagem, que também criam uma nova profissão: a do projetista industrial.

Para poder administrar os novos instrumentos mercadológicos e, ao mesmo tempo, intensificar o seu controle sobre o mercado, o fabricante vê-se obrigado a modificar também a sua estrutura interna de vendas. Em conseqüência, são reexaminadas as formas de determinação de preços e de descontos, e a organização de vendas é adaptada às novas condições. $O$ vendedor passa a ocupar uma posição de maior destaque na empresa, recebendo treinamento mais adequado e melhor bagagem de material e conhecimento de promoção e, acima de tudo, uma remuneração maior. Ademais, ao próprio encarregado da organização de vendas, antes um mero agente entre produtor $e$ comprador, delegam-se poderes de decisão e execução administrativa. Cabe a ele encontrar os melhores meios de integração entre as condições internas e externas da empresa, o que vem obrigá-lo a antecipar e planejar os acontecimentos. O orçamento de vendas deixa de ser um pormenor da contabilidade de custos ou do cálculo financeiro geral, para passar a exercer uma função autônoma em que a distribuição de contas e verbas é avaliada à luz de seu retorno esperado.

A difícil tarefa de previsão de vendas também é delegada ao executivo de marketing. Para poder cumpri-la, este é obrigado a adquirir conhecimentos alheios à sua função direta de vendas, ou seja, conhecimentos de natureza econômica, es-

\section{Sem conhecimento} de informática, o mercadólogo não tem vez.

tatística, legal, financeira, social'e, às vezes, até engenharia industrial. Acima de tudo, no entanto, precisa aprender a manejar o computador, selecionar e manipular software e tomar decisões que conjugam o instintivo com a exatidăo da informática.

A fim de fazer face a esta multiplicidade de funções e para poder tomar suas decisões mais seguras, o mercadólogo se interessa por contratar os serviços de especialistas e embarcar para a terceirização. Além do agente publicitário, beneficiam-se desta tendência sobretudo o consultor administrativo e o pesquisador de mercado. É principalmente com a crescente aceitação das pesquisas de mercado e da informática, que a mercadologia se aproxima de uma atividade com traços científicos, que se inspira em métodos avançados de estatística.

\section{0 "ESPÍRITO SELETIVo" e AS ECONOMIAS EM EXPANSÃO}

Dizem que quando dois brigam um terceiro se diverte. No caso, os conflitos entre os fabricantes e os distribuidores beneficiaram sobremaneira o próprio 
consumidor. Ele torna-se "rei", ele comanda, ele rejeita, mas sempre aceita uma parte da avalanche de produtos e serviços que lhe são oferecidos, porque se ajustam aos seus gostos e porque ele dispōe dos recursos para poder comprá-los. Surgiram assim, em meados deste século, duas tendências fundamentais que moldam o mercado, não só nos Estados Unidos, como também na Europa, que se reergue depois da guerra, e sobretudo no Japão que adota e adapta o marketing à sua maneira para conquistar mercados de exportação. Uma das duas tendências é a transição do mercado comprador, no qual a oferta global de bens veio a superar a procura, colocando o comprador na invejável posição de poder "ditar" ao fabricante o que, quando e como deveria produzir.

A outra tendência, possivelmente mais significativa, apesar de ser intangível, é a intensificação de um fenômeno que, por falta de um termo melhor, chamamos de "espírito seletivo". Referimo-nos àquela atitude crítica em relação aos produtos oferecidos no mercado, que se cria na mente do consumidor com o desenvolvimento da sua consciência e posição social, com o progresso da sua instrução, com o ingresso da mulher na fileira dos trabalhadores e com a conscientização ecológica.

Um número muito maior de pessoas está hoje apto a exercer esse poder de escolha, e bem maior será esse número amanhã. Isto, em parte devido à socialização das massas, em parte dado ao avanço da educação, mas sobretudo em conseqüência da onda ecológica.

As próprias empresas contribuem, diariamente, para alimentar o espírito seletivo, devido a sua ansiedade de conquistar parcelas sempre maiores do mercado em potencial, colocando à disposição do consumidor um vasto material informativo por meio da propaganda e da promoção de vendas. Quanto mais se intensifica esse processo, tanto mais intenso terá que ser o esforço da empresa para se adaptar aos desejos dos seus clientes, a menos que estes se encontrem numa situação de real desvantagem econômica, como nos casos de depressão aguda ou de desemprego em massa.

Do outro, uma nova tendência de mer-

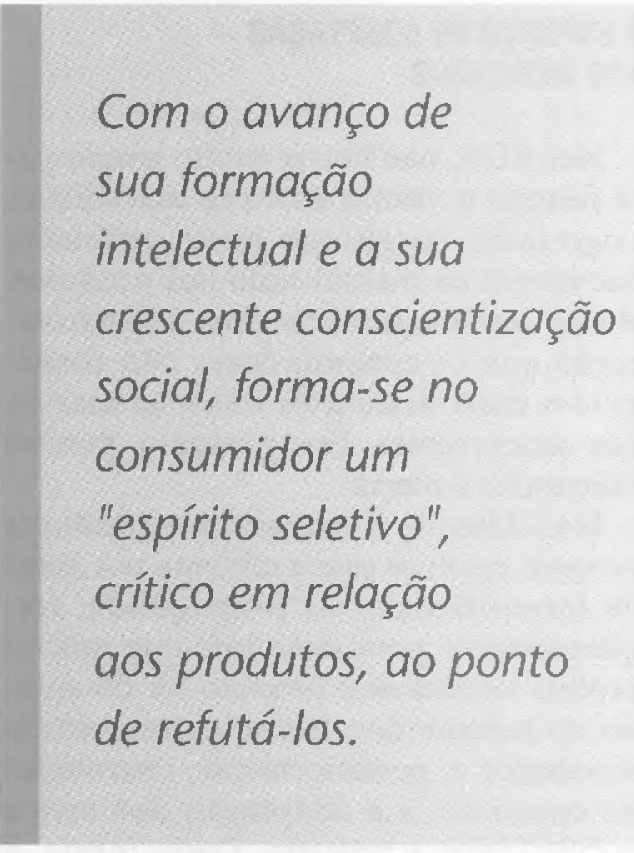

cado beneficia as empresas, ao menos aquelas que souberem se aproveitar desta nova oportunidade, ou seja: a globalização. Com ela, volta-se ao estado anterior da massificação, se bem que agora em termos internacionais. Agora, em todos os países comem-se sanduíches do McDonald's e vestem-se as roupas da Benetton. Mas, as aparências podem enganar, pois um grande mercado não é necessariamente um mercado uniforme. $\mathrm{O}$ big-burger da McDonald's é igual em todo - mundo quanto a sua estrutura básica, mas os ingredientes variam de acordo com o gosto do país. Então, o que temos hoje é uma espécie de massificação controlada em que o produtor procura padronizar ao máximo a sua oferta, mas não pode deixar de observar as diferenças e predileçōes de seus consumidores.

Do exposto, podemos concluir que hoje a existência de um mercado comprador não mais constitui condição exclusiva para tornar a adaptação aos mercados uma necessidade ou, ao menos, uma diretriz recomendável às empresas. $\mathrm{E}$ isto, por sua vez, contém uma inferência importante para as economias que, como a do Brasil, ainda não atingiram o estado pleno de orientação para o consumo: com o avanço educacional, compensa às empresas dedicarem-se intensamente ao estudo das condições que fazem o consumidor optar por um outro produto. 


\section{TENDÊNCIAS PARA A SEGMENTAÇÃO}

Atualmente, o marketing está vivendo uma fase de conflito entre duas tendências estratégicas predominantes. De um lado, tende naturalmente para a crescente massificação, não só para se aproveitar dos mercados mundiais cada vez mais extensos, mas sobretudo devido às grandes vantagens que dela decorrem, como a economia de escala e a padronização dos processos de distribuição e de comunicação. Essas tendências deram um surto fenomenal às agências de publicidade que tornaram-se quase que sinônimos das funções de marketing da última parte do século XX. A estratégia condizente com essa força de massificação, apoiada com campanhas publicitárias de grande vulto, denominamos, em outra parte, de estratégia de difusāo, pois, o objetivo primordial da empresa consiste em difundir os seus produtos o máximo possível sem ter que alterá-lo, usando para isto a força da persuasão.

Mas, há do outro lado uma tendência contrária que busca o sucesso através da adaptaçăo, a mais minuciosa possível, aos gostos dos seus consumidores e que requer a adoção de uma estratégia própria: a estratégia de segmentação. Ela procura tirar proveito do espírito seletivo dos consumidores, da emancipação crescente das mulheres na sociedade, do nível cada vez mais sofisticado de instrução da população, dos diferentes estilos de vida que caracterizam os gostos e as predileçōes de cada grupo social e, evidentemente, também das rendas disponíveis e da localização dos consumidores. ${ }^{19}$

Quem ganhará a corrida? A difusão ou

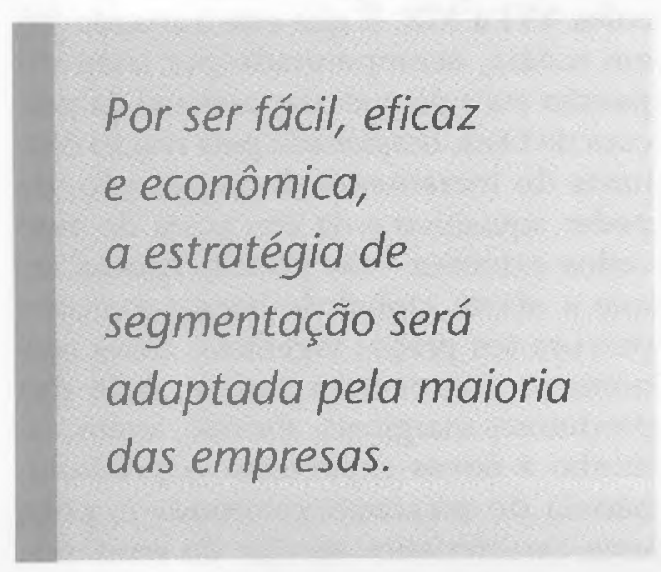

a segmentação? Diríamos que nenhuma das duas em termos absolutos, porque sempre haverá empresas que apostarão em produtos não diferenciados (como a Coca-Cola, por exemplo) e que acreditam no seu sucesso desde que mantenham verbas elevadas de publicidade, amplos sistemas de distribuição e grande apoio às suas marcas. Mas, acredito que a grande maioria das empresas optará pela segmentação e isto por uma razão muito simples: ela tornar-se-á cada vez mais econômica. A razão é o computador, mais especificamente o surto do database, uma maneira simples e cada vez mais barata de colecionar, registrar e dirigir mensagens a indivíduos, cujos perfis e predileções de consumo são conhecidos em mínimos detalhes.

Dentro em breve, faremos todos parte de uma série de banco de dados onde figuram não só o nosso nome e endereço, como também as nossas forças e fraquezas individuais, o nosso poder aquisitivo e a melhor maneira de nos "pegar" para comprar as maravilhas do mundo. Seremos bombardeados pelo marketing direto, não só através de cartas, como também de mensagens eletrônicas, televisionadas ou não, e as nossas compras também serão feitas por comunicação, a partir de descrições e especificações por nós ditadas ao fornecedor através de telefones móveis e vídeos "falantes". Será este o "maravilhoso mundo novo" que Huxley e outros autores nos prometeram?

\section{RESUMO E CONCLUSÕES}

Desde que o homem descobriu as vantagens da especialização do trabalho, existe o intercâmbio de bens e serviços, inicialmente sob a forma de trocas e compensações, depois por intermédio de um comércio organizado. Houve fases na história econômica mundial em que a distribuição constituiu a principal fonte de riqueza e de prestígio social (exemplo: Veneza no século XV). Estas fases, porém, representam a exceção à regra que reserva ao processo técnico de produção o elemento criador que é negado ao comércio.

Sobretudo desde a Idade Média, a funçāo comercial passa a ser relegada a segundo plano na hierarquia administrativa da empresa e, apesar do extraordiná-
19. Ver o primeiro capítulo do livro de RICHERS, Raimar \& PI. MENTA Lima, Cecilia. Segmentação: Opçōes Estratégicas para o Mercado Brasileiro. Nobel, 1991. 
A predominância do mercado vendedor é, pois, uma característica secular da economia capitalista e constitui, ao mesmo tempo, a explicação do modesto status social que o encarregado do setor de vendas ocupa na empresa capitalista.

rio impulso que o comércio recebe, no capitalismo, os problemas de produção continuam a dominar o pensamento empresarial nos séculos XVI a XIX.

No século $X X$, contudo, surge uma tendência de emancipação do comércio e de seu portador, o dirigente comercial ou mercadológico. Quais são as origens dessa tendência, quais são suas características e conseqüências para a empresa de hoje? Ao redor dessas perguntas, gira a presente análise e interpretação.

Sob o risco de simplificarmos demasiado a realidade, mas a favor da clareza de posição, passaremos a responder a essas perguntas de forma resumida e esquemática, procurando esclarecer a rela'ção existente entre deferminadas inovações de ordem social ou econômica e suas conseqüências para a empresa e o seu dirigente.

Inicialmente, convém dividir-se o movimento histórico em duas fases de características distintas: a primeira coincide com o nascimento e a evolução do capitalismo; a segunda poderá ser rotulada como "fase de transição" - para onde não podemos precisar, mas certamente não será uma volta ao domínio da produção. Por enquanto, há indícios claros de que o domínio será do consumidor e nada sugere uma mudança no paralelograma dos poderes.

\section{A. Fase do capitalismo}

1. Inovação: o propósito de lucro. O desejo de auferir um lucro maior que o indispensável à sobrevivência rompe a economia fechada prevalecente até o fim da Idade Média.

Conseqüência: a criação da empresa capitalista. Esta visa, por meio da acumulação de lucros, a aumentar continuadamente o seu patrimônio, tanto pessoal quanto material.

2. Inovação: a conquista de mercados. Nos séculos XV a XVII criam-se novas formas de comércio, como o atacado em larga escala, os bancos comerciais e as bolsas. No âmbito internacional, a expansão recebe grandes impulsos pela descoberta das Américas e do caminho marítimo ao Oriente.

Conseqüiência: a separação geográfica entre o produtor e consumidor. Ampliam-se as oportunidades de negócios, mas o controle dos mercados é dificultado.

3. Inovação: as invençōes técnicas e a divisão do trabalho. A manufatura transformase em indústria, sobretudo desde a Revolução Industrial.

Consequiência: a produção em massa. Traz consigo a especialização geográfica, a racionalização e a redução dos custos unitários, mas também o aumento do risco de não-venda, devido à necessidade de produzir-se para o estoque em vez de sob encomenda.

Ao conjugar esses fatores, podemos melhor compreender porque e como o capitalismo conseguiu manter-se, apesar do fenomenal aumento da capacidade de fabricação que se pôde observar nos séculos XVI a XIX. É que este aumento foi, em média, acompanhado por uma expansão mais do que proporcional da procura de bens, ocasionada pela reação conjunta do incremento da população, do poder aquisitivo e da conquista de mercados externos. Nas poucas épocas em que a oferta global de bens superou a procura (os preços vigentes), crises econômicas provocaram a eliminação dos produtores marginais, abrindo, assim, caminho a novas expansões. A predominância do mercado vendedor é, pois, uma característica secular da economia 
capitalista e constitui, ao mesmo tempo, a explicação do modesto status social que o encarregado do setor de vendas ocupa na empresa capitalista.

Podemos, de tudo isso, concluir que o capitalismo criou as condições técnicas, mas não o ambiente econômico essencial à emancipação do comerciante.

\section{B. Fase de transição}

1. Inovação: a criação de produtos padronizados. É uma decorrência da produção em massa, sobretudo desde que a linha de montagem e, mais tarde, os processos de automação permitem (e freqüentemente exigem) uma fabricação de bens a custos e preços reduzidos, acessíveis a um grande número de compradores e sem características físicas substanciais que permitam a distinção de produtos concorrentes.

Consequiencia: a necessidade de diferenciação. A padronização física obriga cada produtor a criar condições que tornem o seu produto distinto dos produtos concorrentes, seja por meio da diferenciação do próprio produto (marca, embalagem, rotulagem, modelo, cor, capacidade etc.), seja pela maneira de mercadizá-lo (vias de distribuição, promoção ou satisfação de após-compra).

2. Inovação: a transição para o mercado comprador. Com a expansão industrial, a perda de contato direto com o freguês e a necessidade de se produzirem quantidades substanciais para o estoque, a oferta global de bens tende a superar a sua procura.

Consequiência: a necessidade de se conquistar novos mercados. Sendo baixas as margens de lucro por unidade e altos os custos fixo da produção em massa, a flexibilidade de preços torna-se limitada. A sobrevivência ou expansão da produção depende da conquista de novas oportunidades de venda, tanto em extensão geográfica, quanto por meio de inovações e, mais tarde, pela criação de obsolência planejada.

3. Inovação: o despertar do "espírito seletivo". Devido à consciência social e ao progresso da educação, um maior número de indivíduos torna-se capaz de escolher mais criteriosamente entre os produtos oferecidos na praça.
Quanto mais valioso o produto tanto mais a futura concorrência girará em torno de indivíduos e ofertas adaptadas a gostos e especificações pessoais.

Conseqüência: a necessidade de orientar as decisões a partir do mercado. $O$ crescente conhecimento de causa do consumidor e a sua atitude sempre mais crítica face ao produto obrigam a empresa a tomar decisões de produção e distribuição baseadas nas preferências e nos desejos do comprador.

4. Inovação: a atomização do mercado. $\mathrm{O}$ avanço da tecnologia da computação e seus custos cada vez menores, conjugado à formação de pequenos grupos sociais com predileções e hábitos de consumo distintos entre si, permite que a empresa obtenha informações muito valiosas sobre cada um dos grupos sociais e até individuos.

Conseqüência: a necessidade de montar $e$ manter um banco de dados da clientela. Ao se concentrar na seleção daqueles clientes que constituem um mercado natural para cada empresa, esta segmenta quase que obrigatoriamente. Com isto poderá atender a sua clientela em função de desejos e necessidades autênticas de consumo. Quanto mais valioso o produto tanto mais a futura concorrência girará em torno de indivíduos e ofertas adaptadas a gostos e especificações pessoais. Assim, mesmo os produtos mais massificados sofrerão pequenos ajustes em função de grupos sociais relativamente homogêneos e coesos entre si. ${ }^{20}$

Como o conjunto desses quatro fatores age na mesma direção, ele tende a ser cumulativo e muito poderoso. Esse poder se transfere para o executivo de marketing, que assume posições cada vez mais poderosas e influentes na empresa. $\square$
20. RICHERS, Raimar. O Futuro do Marketing e o Marketing do Futuro. Revista de Administraఢ̧ão. São Paulo, FEA/USP, 2f(4), outubro/novembro 1986. 